\title{
Mecanismos moleculares de la amelogénesis imperfecta. Una revisión de los genes ENAM, AMBN, FAM83H, MMP20 y KLK4.
}

\author{
Molecular mechanisms of amelogenesis imperfecta. A review \\ of the ENAM, AMBN, FAM83H, MMP20 and KLK4 genes. \\ Mecanismos moleculares da amelogênese imperfeita. Uma revisão \\ dos genes ENAM, AMBN, FAM83H, MMP20 e KLK4.
}

\author{
Nicolás Pescetto ${ }^{1}$ (D) 0000-0002-6791-8911 \\ Alberto Céspedes ${ }^{2}$ (D) 0000-0003-1872-9644 \\ Ronell Bologna Molina² ${ }^{2}$ 0000-0001-9755-4779 \\ Vanesa Pereira Prado² (DD 0000-0001-7747-6718
}

\section{Resumen}

La amelogénesis imperfecta (AI) es un trastorno hereditario que afecta la estructura y apariencia clínica del esmalte dental. Hasta la fecha, se han asociado las mutaciones de 18 genes como la etiología de la AI no sindrómica. El objetivo de este trabajo es actualizar los conocimientos vigentes acerca de los genes ENAM, AMBN, FAM83H, MMP20 y KLK4 causantes de los diferentes tipos de AI.

Metodología: Se realizó una búsqueda bibliográfica considerando artículos científicos desde el 2003 al 2021 sobre mutaciones en los genes mencionados en los siguientes portales: scielo, Pubmed/MEDLINE, Cochrane y Springer Link.

Resultados: 37 artículos cumplieron los criterios de inclusión y fueron utilizados para esta revisión.

Conclusiones: Dependiendo del gen implicado, las alteraciones del esmalte pueden mostrar una variedad de características. Los mecanismos biológicos que conducen a la enfermedad son múltiples y variados, sin embargo, muchos de ellos no están del todo claro aún, por lo que se requerirá de más investigaciones para mejorar nuestra comprensión del tema.

Palabras clave: amelogénesis imperfecta, hipoplasia, esmalte.

Facultad de Odontología, Universidad de la República, Uruguay.

Área de Patología Molecular Estomatológica, Facultad de Odontología, Universidad de la República, Uruguay. vanesapereira91@ hotmail.com

Fecha de recibido: $x x x x x x x x x x x x$ - Fecha de aceptado: $x x x x x x x x x x x x$ 


\section{Abstract}

Amelogenesis imperfecta (AI) is an inherited disorder that affects the structure and clinical appearance of tooth enamel. Mutations of 18 genes have been associated as the etiology of AI. The objective of this work is to update the current knowledge about ENAM, AMBN, FAM83H, MMP20 and KLK4 genes that cause the different types of AI.

Methodology: A bibliographic search was carried out considering scientific articles from 2003 to 2021 with regard to specific mutations in the aforementioned genes in the following portals: scielo, Pubmed / MEDLINE, Cochrane and Springer Link.

Results: 37 articles met the inclusion criteria and were used for the development of this review.

Conclusions: Depending on the gene involved, enamel alterations can show a variety of characteristics. The biological mechanisms that lead to the disease are multiple and varied, however many of them are not entirely clear yet, so more research will be required to improve our understanding of the subject.

Keywords: amelogenesis imperfecta, hypoplasia, enamel.

\section{Introducción}

En el proceso de formación del diente, más específicamente durante la amelogénesis, se pueden generar alteraciones que se traducirán más tarde como defectos en el esmalte dental. Dentro de estas alteraciones se encuentra la amelogénesis imperfecta (AI) la cual se define como un grupo heterogéneo de defectos hereditarios en la función de los ameloblastos y la mineralización de la matriz del esmalte, lo que produce dientes con múltiples anomalías en dicha

\section{Resumo}

A amelogênese imperfeita (AI) é uma doença hereditária que afeta a estrutura e aparência clínica do esmalte dentário. Mutações de 18 genes têm sido associadas como causa do AI. O objetivo deste trabalho é atualizar o conhecimento atual sobre genes ENAM, AMBN, FAM83H, MMP20 e KLK4 que causam os diferentes tipos de IA.

Metodologia: Foi realizada uma busca bibliográfica considerando artigos científicos de 2003 até 2021 sobre mutações específicas nos genes citados nos seguintes portais: scielo, Pubmed / MEDLINE, Cochrane e Springer Link.

Resultados: 37 artigos atenderam aos critérios de inclusão e foram utilizados para o desenvolvimento desta revisão.

Conclusóes: Dependendo do gene envolvido, as alteraçóes do esmalte podem apresentar uma variedade de características. Os mecanismos biológicos que levam à doença são múltiplos e variados, porém muitos de les ainda não estão totalmente esclarecidos, portanto, mais pesquisas serão necessárias para melhorar nossa compreensão do assunto.

Palavras-chave: amelogênese imperfeita, hipoplasia, esmalte.

capa, ya sea de forma generalizada o localizada, pudiendo afectar tanto la dentición primaria como permanente ${ }^{(1)}$.

Aunque son muchas las clasificaciones que se han propuesto para la AI, la más utilizada en la actualidad es la clasificación de Witkop ${ }^{(2)}$, la cual la divide en cuatro grupos principales: hipoplásica, hipocalcificada, hipomadurativa e hipomadurativa-hipoplásica con taurodontismo, dependiendo de la presentación clínica de los defectos del esmalte. Cada grupo principal de AI puede dividirse adicionalmente en varios 
subgrupos según el modo de herencia: autosómica dominante, autosómica recesiva o ligado al cromosoma $\mathrm{X}^{(2,3)}$ (Tabla 1). Los parámetros usados para esta clasificación son espesor, dureza y textura del esmalte afectado, así como su presentación radiográfica. Varios autores determinan que existen diferencias en los mismos para establecer el momento en que ocurrió la alteración ${ }^{(4,5)}$.

Tabla 1. Clasificación de Witkop de la Amelogénesis Imperfecta

\begin{tabular}{|c|l|}
\hline Tipo I & Hipoplásica \\
\hline IA & Foveal, autosómica dominante \\
\hline IB & Localizada, autosómica dominante \\
\hline IC & Localizada, autosómica recesiva \\
\hline ID & Lisa, autosómica dominante \\
\hline IE & Lisa, dominante, ligada al cromosoma X \\
\hline IF & Rugosa, autosómica dominante \\
\hline IG & Agenesia del esmalte, autosómica recesiva \\
\hline Tipo II & Hipomadurativa \\
\hline IIA & Pigmentada, autosómica recesiva \\
\hline IIB & Recesiva, ligada al cromosoma X \\
\hline IIC & Dientes con gorro de nieve, autosómica dominante \\
\hline Tipo III & Hipocalcificada \\
\hline IIIA & Autosómica dominante \\
\hline IIIB & Autosómica recesiva \\
\hline Tipo IV & Hipomadurativa-Hipoplásica con taurodontismo \\
\hline IVA & Hipomadurativa-hipoplásica con taurodontismo, \\
\hline IVB & autosómica dominante \\
\hline
\end{tabular}

Clasificación de la AI propuesta por Witkop, en función del fenotipo y secundariamente por el modo de herencia ${ }^{(2)}$.

A su vez, el tipo de AI también varía de acuerdo con el gen afectado y la mutación que presente (6) Los primeros casos fueron hallados en los genes codificadores de las principales proteínas de la matriz del esmalte: AMELX (amelogenina), asociado a la AI de tipo hipoplásica como hipocalcificada, AMBN (ameloblastina) y ENAM (enamelina), asociados a una AI tipo hipoplásica ${ }^{(7)}$. Posteriormente se relacionó con más genes como los codificantes de las proteinasas del esmalte, siendo los principales el MMP20 y $K L K 4$, dando como resultado un esmalte hipomineralizado ${ }^{(8)}$.

Actualmente, una gran cantidad de genes involucrados en diferentes aspectos del proceso de amelogénesis se relacionan con la AI no sindrómica, dando un total de 18 genes afectados ${ }^{(6,9)}$. Entre los más relevantes se encuentra el FAM $83 \mathrm{H}$, cuyas mutaciones causan una severa $\mathrm{AI}$ autosómica dominante hipocalcificada, la cual se cree que es la más común en América del Norte y es foco de múltiples estudios ${ }^{(10,11)}$. Debido a la compleja etiología de esta patología, el presente estudio tiene como objetivo realizar una actualización de la literatura sobre los genes más relacionados con los diferentes tipos de amelogénesis imperfecta: ENAM y $A M B N$ para la forma hipoplásica, $F A M 83 H$ para la forma hipocalcificada y MMP20 y KLK4 para la forma hipomadurativa.

\section{Metodología}

Se realizó una búsqueda de artículos científicos originales en los siguientes portales: Pubmed/ MEDLINE, Cochrane, Springer Link y scielo. Se utilizaron las combinaciones de palabras claves: "amelogénesis imperfecta" más el operador AND seguido de "ENAM", "AMBN", "FAM83H”," MMP20" y “ KLK4”. Como filtros de búsqueda se seleccionó el idioma español e inglés, desde el 2003 al 2021. Se excluyeron aquellos artículos en los cuales se relacionaran a los genes con otras patologías, o donde se relacionara a la AI con otros genes. La estrategia de búsqueda y sus resultados se sintetizan en la Tabla 2.

\section{Resultados}

Fueron revisados los títulos y resúmenes de todos los artículos encontrados con las palabras 
clave y aquellos que cumplieron los criterios de inclusión se seleccionaron para esta revisión.

La búsqueda inicial recabó un total de 206 publicaciones, de las cuales 37 fueron incluidas, y 5 artículos adicionales identificados por otros medios (referencias realizadas por los propios autores). La información recopilada se sistematizó en tres secciones: una dedicada a los genes $E N A M$ y $A M B N$ causantes de AI tipo hipoplásica, otra al gen FAM83H causante de AI tipo hipocalcificada y una tercera a los genes MMP20 y KLK4 causantes de AI tipo hipomadurativa. El resumen de los genes revisados se sistematiza en la Tabla 3.

\section{Tabla 2. Estrategia de búsqueda y resultados} obtenidos.

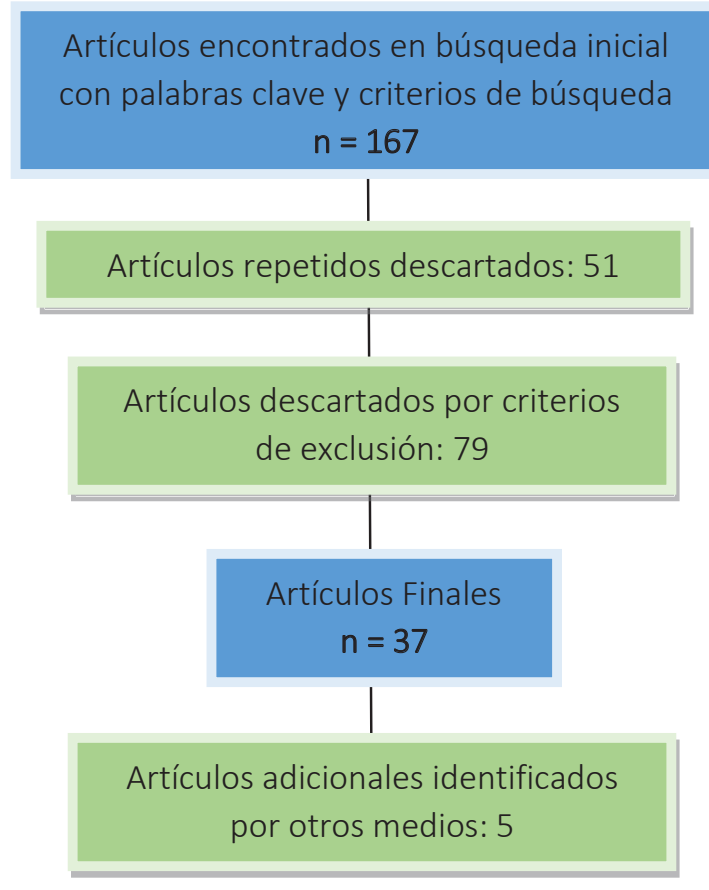

\section{Genes relacionados con la amelogénesis imperfecta hipoplásica}

\section{ENAM}

Hasta el momento, son 22 el número de mutaciones en el gen ENAM detectadas en humanos que causan $\mathrm{AI}$, estas incluyen pequeñas deleciones e inserciones que cambian el marco de lectura y truncan la proteína codificada ${ }^{(12)}$. El fenotipo en el esmalte hipoplásico se caracteriza por ser muy variado, desde pequeńos hoyos a surcos horizontales, principalmente en las caras libres de piezas anteriores, hasta casos donde la pérdida de esmalte es casi completa ${ }^{(12,13)}$. Al examen radiográfico es común encontrar un esmalte más o menos delgado con una radio densidad normal o similar a la dentina, o casos donde puede estar prácticamente ausente ${ }^{(12,13)}$. Es posible observar un fenotipo de esmalte normal en individuos con mutaciones ENAM, incluso donde otros miembros de la familia con la misma mutación si presentaron AI hipoplásica severa. Solo las mutaciones ENAM han mostrado esta falta de penetrancia entre las causantes de AI ${ }^{(13-15)}$. Se han propuesto algunas explicaciones para determinar esta variabilidad clínica. En el caso de mutaciones recesivas, éstas se manifestarían con un efecto sumatorio, es decir que el fenotipo es más leve o imperceptible cuando un solo alelo es defectuoso, en comparación con casos en que ambos lo son ${ }^{(14,16)}$. Koruyucu et al. Explican esta variabilidad por la ubicación de la mutación en el exón terminal, la cual se traduciría en una proteína truncada, con función de enamelina parcial, siendo menos dañina ${ }^{(13)}$.

Histopatológicamente se han visto diferentes alteraciones en la arquitectura del esmalte: puede ser similar a una pieza normal en el esmalte superficial, con cristales bien orientados y empaquetados, pero con una falta general de estructura y fusión de cristales cerca de la unión amelo-dentinaria, contrariamente puede observarse una capa interna normal y una exterior estructuralmente anormal ${ }^{17,18)}$. Está claro que la enamelina juega un papel importante en la organización estructural del esmalte, pero la forma en que una alteración en la misma afecta al esmalte puede ser muy diferente.

Brookes et al. Explicaron esta transición de una estructura interna normal a una anormal en respuesta a un estrés del retículo endoplasmático rugoso (RER) ${ }^{(18)}$. Cuando las proteí- 
nas truncadas se acumulan en el lumen del RER, desencadena una respuesta de proteína desplegada en un intento de aliviar el estrés y restaurar la homeostasis. Esto perturba la función del ameloblasto en un momento dado de la etapa secretora, que resulta en un cambio de producción de esmalte normal a un esmalte estructuralmente anormal. Al microscopio electrónico los ameloblastos afectados mostraron que contenían grandes vesículas intracelulares con retención de proteínas del esmalte. Los ratones homocigotos fueron más severamente afectados ya que ambas copias de ENAM estaban mutadas, lo que duplica la concentración de ENAM mutado en comparación con los heterocigotos. Esto podría aumentar el estrés del RER generado durante el tráfico intracelular que conduce a una respuesta más severa y una apoptosis celular ${ }^{(18)}$. Esto apoya la idea que la AI ligada a $E N A M$ tiene un efecto dependiente de la dosis ${ }^{(14,16)}$.

\section{AMBN}

El gen $A M B N$ es el responsable de codificar a la ameloblastina, una de las tres proteínas principales de la matriz del esmalte, por lo cual siempre se estimó que una alteración en su estructura podría conducir a una AI ${ }^{(19)}$. Para Poulter et al. La implicación de la ameloblastina en la adhesión de los ameloblastos jugaría un papel importante ${ }^{(20)}$. Esto es apoyado en investigaciones con ratones $A M B N$ mutantes, donde la capa de ameloblastos se desprende de la matriz del esmalte y el proceso de Tomes no se desarrolla, dando como resultado un fenotipo de AI hipoplásica ${ }^{(21)}$.

La escasez de casos de mutaciones $A M B N$ responsables de la $\mathrm{AI}$ podrían deberse a su modo de herencia recesivo ${ }^{(19)}$. Otra razón podría ser que el gen $A M E L X$ compensaría, de forma parcial, la deficiencia de $A M B N$, dado que los dos genes están relacionados filogenéticamente compartiendo algunas similitudes ${ }^{(21)}$. Por lo tanto, en caso de mutaciones homocigóticas, la compensación de ameloblastina por ameloge- nina podría contribuir a eliminar los posibles defectos dentales o dificultar su detección ${ }^{(19)}$. Las características clínicas en los pacientes portadores de estas alteraciones siguen un patrón común con pequeńas variaciones, tanto en dentición temporaria como permanente: esmalte de espesor reducido, rugoso y susceptible al desgaste ${ }^{(20,23,24)}$.

Lu et al. Examinaron a once individuos afectados, y observó que el esmalte se desprendía debido a alteraciones en la unión amelo-dentinaria, dejando una dentina expuesta hipomineralizada, por lo que se perdía rápidamente al desgaste. El contorno de la unión amelo-dentinaria se incrementa en ancho, y la estructura de transición normalmente ondulada se convirtió en una línea recta en apariencia ${ }^{(24)}$. Algunos individuos, a pesar de ser jóvenes, también presentaban severos problemas periodontales, reabsorción ósea y gran movilidad dental ${ }^{(24)}$.

En observaciones con microscopía electrónica, los casos más severos se presentan con una gran reducción del espesor del esmalte, de la densidad mineral y ausencia de cualquier arquitectura normal ${ }^{(20)}$. En otros casos, la estructura prismática de las piezas afectadas se mantiene prácticamente intacta, pero la cantidad de prismas disminuye ${ }^{(20,24)}$

Una característica única observada en ratones con nula expresión de $A M B N$ es la acumulación de material orgánico contra la superficie de dentina, formado principalmente por amelogenina, sin formación de cristales del esmalte. Al no haber un alargamiento de estos cristales, los ameloblastos no pueden iniciar el crecimiento aposicional y expandir el esmalte en espesor, por lo que la amelogenina se acumula contra la dentina mineralizada después de su secreción. A pesar de que la amelogenina es un componente fundamental para la formación de la matriz, solo puede funcionar correctamente en conjunto con un frente de mineralización que inicia con la formación de los primeros cristales de esmalte, lo que requiere de ameloblastina ${ }^{(23)}$. 


\section{Genes relacionados con la amelogénesis imperfecta hipomineralizada}

\section{FAM83H}

Las mutaciones del gen FAM83H causan AI hipocalcificada autosómica dominante ${ }^{(11)}$. Hasta el momento son 32 las mutaciones FAM83H que se han informado, todas en el exón 5 del gen ${ }^{(25)}$. La mayoría se trata de mutaciones sin sentido o de desplazamiento de marco, las cuales llevan a la terminación prematura de la traducción y generan una proteína truncada que incluyen solo el extremo $\mathrm{N}$-terminal $(7,26)$

Varios estudios han determinado que un cambio en la cantidad expresada de proteína $F A$ $\mathrm{M} 83 \mathrm{H}$ no conduce a un fenotipo de enfermedad, por lo que una haploinsuficiencia no sería la causa de las afecciones en el esmalte. Por el contrario, un efecto negativo o de ganancia de función serían los mecanismos en que la proteína truncada desencadenaría la enfermedad (27-29).

Las manifestaciones clínicas siguen un conjunto de patrones comunes: un esmalte rugoso, blando, de coloración marrón-amarillento, el cual es susceptible al desgaste, lo que causa una rápida pérdida del espesor, conservándose comúnmente en pequeñas zonas en cervical y en las puntas de las cúspides, pudiendo considerarse una característica típica por mutación FAM83H ${ }^{(25,27,29)}$. También se asoció con hipersensibilidad dentaria a estímulos térmicos, gingivitis generalizada y aumento de las fracturas coronarias ${ }^{(26,30)}$.

Radiográficamente lo más destacable es la radio densidad similar entre el esmalte y la dentina, y la presencia de esmalte de aparente espesor normal en piezas no erupcionadas, lo que indicaría que la cantidad de proteína secretada por el ameloblasto no está influenciada directamente por las mutaciones en $F A M 83 H^{(25,26,29,30)}$

A nivel histopatológico se han observado defectos en los prismas del esmalte: con una dirección irregular, una disminución en su número y con espacios interprismáticos ensanchados, siendo más evidente en la unión amelo-dentinaria (29, 31). También se detectó una mayor retención de proteínas y reducción de minerales, haciendo que el esmalte se desgaste fácilmente y funcione como un mal aislante térmico ocasionando hipersensibilidad $^{(26,32)}$.

De los hallazgos relacionados con la proteína expresada por $F A M 83 H$, se observó que ésta interactúa con la caseína quinasa 1 (CK-1), la cual está localizada en filamentos de queratina en los ameloblastos ${ }^{(27,33)}$. Se propuso entonces que la proteína FAM83H podría funcionar como un regulador en la organización del citoesqueleto del ameloblasto, como una proteína andamio y guiando a CK-1 a su ubicación fisiológica. Las mutaciones FAM83H provocarían la desorganización del citoesqueleto al no reclutar CK-1 a los filamentos de queratina, defecto que se extendería a los desmosomas, interfiriendo consecuentemente con la formación y función de los ameloblastos ${ }^{(30,33)}$. A su vez, en estudios in vitro, tanto en células de riñón embrionario humano, como en células dentales de ratón, una alta concentración de la proteína FAM83H mutada se localizó en el núcleo, lo que reduce su cantidad en el citoplasma a un nivel por debajo de lo necesario para un funcionamiento normal. Esta localización nuclear podría contribuir a la incorrecta organización del citoesqueleto de queratina ${ }^{(29-31)}$.

\section{Genes relacionados con la amelogénesis imperfecta hipomadurativa}

\section{MMP20}

El gen MMP20 codifica la metaloproteinasa de la matriz 20, enzima que escinde las proteínas de la matriz, mayormente la amelogenina, así como enamelina y ameloblastina ${ }^{(34)}$. Hasta la fecha se han informado un total de 18 mutaciones de MMP2O que causan AI, las cuales se distribuyen uniformemente a lo largo de los 10 exones que conforman el gen, a excepción del exón 8 y 9. Se trata en gran parte de mutaciones sin sentido, cambio de marco o mutaciones en 
el sitio de empalme, las cuales en su mayoría el ARN mensajero sería degradado luego de su transcripción, provocando una expresión nula del alelo mutado ${ }^{(35)}$.

Las características clínicas observadas son las de una AI hipomadurativa en donde se destaca un esmalte con una coloración marrón-amarillenta, a veces poroso, más opaco que un esmalte normal y con un relativo desgaste en los bordes incisales y puntas de cúspides ${ }^{(34-36)}$. En los casos más severos, el esmalte se desgasta rápidamente con las fuerzas oclusales luego de la erupción de la pieza, dejando dentina expuesta y provocando sensibilidad dentaria ${ }^{(34,36)}$.

En el examen radiográfico siempre se observa un patrón de esmalte con un contraste leve o apenas visible en comparación con la dentina marcando la reducción de carga mineral ${ }^{(34-37)}$. Pruebas de nanodureza del esmalte muestran que las capas más superficiales, así como las más cercanas al límite amelo-dentinario, tienen aproximadamente un $50 \%$ de la dureza de un esmalte normal, mientras que la capa media entre estas dos es la más afectada, superando apenas el $10 \%$ de lo normal ${ }^{(35)}$.

Seymen et al. Proponen que la severidad con que se manifiesta el fenotipo depende de si la mutación MMP20 codifica un metaloproteinasa con una capacidad funcional activa, aunque reducida, o si su función es completamente nula ${ }^{(36)}$. Esto es observado en estudios in vitro donde la expresión de la proteína mutada era igual que la normal, pero su concentración en el medio acondicionado era poca o nula, posiblemente por un cambio en su estructura que no le permitía ser secretada, o porque era rápidamente degradada debido a su inestabilidad. En estos casos se vieron las alteraciones del esmalte más severas, en comparación con mutaciones donde la proteína sí se encontraba en el medio, manteniendo una función proteolítica de forma parcial ${ }^{(36-38)}$. Esto demostraría que el mecanismo a través del que causa la enfermedad sería una pérdida/disminución de función.
Las proteínas MMP20 y la KLK4 tienen funciones sinérgicas, escindiendo las proteínas del esmalte y facilitando su eliminación, comenzando la primera en la etapa de secreción de la amelogénesis y sumándose la segunda en la etapa de maduración del esmalte ${ }^{(4,39)}$. En estudios con ratones heterocigotos únicos para mutaciones tanto de MMP20 como de KLK4, el esmalte se mostró con una apariencia clínica normal, pero esto cambió en ratones heterocigotos dobles, donde sí se vio alterado, aumentando la porosidad de la superficie y la susceptibilidad al desgaste. Esto sugiere que MMP20 y la KLK4 tienen funciones complementarias, y una alteración combinada de ambas provocaría una $\mathrm{AI}$ por un efecto sumatorio ${ }^{(39)}$.

\section{KLK4}

Las mutaciones del gen $K L K 4$ dan como resultado una AI tipo hipomadurativa ${ }^{(40)}$. Hasta el momento se han informado solo 4 mutaciones diferentes en este gen determinando que es una causa relativamente rara de AI. De estas mutaciones, las dos primeras son un cambio de marco y una mutación sin sentido, en ambas el ARN mensajero sería degradado luego de su transcripción ${ }^{(41,42)}$. Las otras dos se tratan de un cambio de marco que afectan a los codones en el exón final y escaparían al sistema de degradación, dando como resultado una proteína mutada ${ }^{(36,40)}$. Sin embargo, Seymen et al. Observaron que la expresión de la proteína mutada se redujo mucho luego de su secreción en comparación con los controles, haciéndola más propensa a ser degradada ${ }^{(36)}$.

La presentación clínica es típica para la AI hipomadurativa: piezas con esmalte de espesor normal, pero con desmineralización generalizada, y una ligera decoloración marrón-amarillenta $(36,40)$.

A nivel radiográfico se destaca una reducción de la radio densidad del esmalte en comparación con una pieza normal ${ }^{(36)}$.

Se observó a través de diferentes técnicas de microscopía electrónica y tomografía computari- 
zada una diferencia en la estructura de las capas internas del esmalte donde la hipomineralización es mayor, sobretodo en la unión amelodentinaria, en comparación con las capas más externas. En lecturas de microdureza se mostró que el esmalte de la superficie es más duro que la capa de esmalte interior ${ }^{(40)}$. Estos resultados son comparables con estudios en ratones con nula expresión de $K L K 4$, donde a pesar de que el esmalte fuera de espesor normal y al microscopio el patrón de los prismas fuera normal, el mismo se encuentra hipomineralizado, mayormente en las capas más internas ${ }^{(39)}$.

La actividad comprometida de KLK4 mutado reduciría considerablemente la proteólisis y dificultaría la difusión de los péptidos residuales de las capas del esmalte más profundas a las superficiales donde son endocitados por los ameloblastos, ocasionando una retención de proteínas dentro del esmalte profundo, inhibiendo el crecimiento de los cristales durante la etapa de maduración ${ }^{(40)}$.

Tabla 3. Resumen de los principales genes relacionados con la AI

\begin{tabular}{|c|c|c|c|c|c|c|}
\hline Gen & $\begin{array}{c}\text { Localización } \\
\text { cromosómica }\end{array}$ & $\begin{array}{c}\text { No de } \\
\text { exones }\end{array}$ & Proteína codificada & $\begin{array}{c}\text { No de } \\
\text { mutaciones }\end{array}$ & $\begin{array}{c}\text { Tipo de Al asociada } \\
\text { Modo de } \\
\text { herencia }\end{array}$ \\
\hline ENAM & $4 q 13.3$ & 10 & Enamelina & 22 & Hipoplásica & AD/AR \\
\hline AMBN & $4 q 13.3$ & 13 & Ameloblastina & 5 & Hipoplásica & AR \\
\hline FAM83H & $8 q 24.3$ & 5 & Proteína FAM83H & 32 & Hipocalcificada & AD \\
\hline MMP20 & $11 q 22.2$ & 10 & Metaloproteinasa 20 & 18 & Hipomadurativa & AR \\
\hline KLK4 & $19 q 13.41$ & 5 & Calicreina 4 & 4 & Hipomadurativa & AR \\
\hline
\end{tabular}

Características de los genes analizados, relacionados al tipo de AI y número de mutaciones causales. AD: autosómico dominante, AR: autosómico recesivo

\section{Conclusiones}

Las mutaciones de los genes $E N A M, A M B N$, FAM83H, MMP20 y KLK4 son responsables de los diferentes tipos de AI, siendo FAM83H el gen con más mutaciones reportadas hasta el momento.

Las características clínicas del esmalte afectado y el tipo de AI que se manifiesta dependen del gen involucrado y de la mutación causal. Poder relacionar el aspecto clínico y radiográfico del esmalte afectado con el posible origen genético de la AI permitirá implementar métodos diag- nósticos más exactos y lograr un pronóstico más preciso, como también brindar información de riesgo a otros miembros de la familia.

Los procesos y los mecanismos biológicos que conducen a la AI son múltiples y variados, más investigaciones con un enfoque molecular permitirán mejorar la compresión de estos mecanismos e identificar nuevas mutaciones o genes. Estos nuevos conocimientos resultarán en una mejor atención para los pacientes y el desarrollo de nuevas terapias destinadas a minimizar o eliminar los problemas que acarrea la AI. 


\section{Referencias}

1. Sapp J.P; Eversole L.R; Wysocki G.P. Patología oral y maxilofacial contemporánea, 2º edición. Madrid: Elsevier, 2005: 14-16.

2. Witkop C.J. Jr. Amelogenesis imperfecta, dentinogenesisimperfecta and dentin dysplasia revisited: problems in classification. J. Oral. Pathol. 1988; 17(9-10): 547-553.

3. Crawford P.J; Aldred M; Bloch-Zupan A. Amelogenesis imperfecta. Orphanet J. Rare. Dis. 2007; 2: 17.

4. Hu J.C; Chun Y.H; Al Hazzazzi T; Simmer J.P. Enamel formation and amelogenesis imperfecta. Cellstissuesorgans. 2007; 186(1): 78-85.

5. Aldred M.J; Crawford P.J.M; Savarirayan R. Amelogenesis imperfecta: a classification and catalogue for the 21st century. Oral. Dis. 2003; 9(1): 19-23.

6. Prasad M.K; Laouina S; El Alloussi M; Dollfus H; Bloch-Zupan A. Amelogenesis imperfecta: 1 family, 2 phenotypes, and 2 mutated genes. J. Dent. Res. 2016; 95(13): 1457-1463.

7. Smith C.E.L; Poulter J.A; Antanaviciute A; Kirkham J; Brookes S.J; Inglehearn C.F; Mighell A.J. Amelogenesis Imperfecta; Genes, Proteins, and Pathways. Front. Physiol. 2017; 8: 435.

8. Kim J.W; Simmer J.P; Lin B.P.L; Seymen F; Bartlett J.D; Hu J.C.C. Mutational analysis of candidate genes in 24 amelogenesis imperfecta families. Eur. J. Oral. Sci. 2006; 114(suppl1): 3-12.

9. Simancas-Escorcia V; Natera A; Acosta de Camargo M.G. Genes involved in amelogenesis imperfecta. Part I. Rev. Fac. Odontol. Univ. Antioq. 2018; 30(1): 105-120.

10. Lee S.K; Lee K.E; Jeong T.S; Hwang Y.H; Kim S; Hu J.C.C; Simmer J.P; Kim J.W. FAM83H mutations cause ADHCAI and alter intracellular protein localization. J. Dent. Res. 2011; 90(3): 377-381.

11. Kim J.W; Lee S.K; Lee Z.H; Park J.C; Lee K.E; Lee M.H. FAM83H mutations in families with autosomal-dominant hypocalcified amelogenesis imperfecta. Am. J. Hum. Genet. 2008; 82(2): 489-494.

12. Zhang H; Hu Y; Seymen F; Koruyucu M; Kasimoglu Y; Wang S.K; Wright J.T; Havel M.W; Zhang C; Kim J.W; Simmer J.P; Hu J.C.C. ENAM mutations and Digenic Inheritance. Mol. Genet. Genomic Med. 2019; 7(10): e928.

13. Koruyucu M; Kang J; Kim Y.J; Seymen F; Kasimoglu Y; Lee Z.H; Shin T.J; Hyun H.K; Kim Y.J; Lee S.H; Hu J.C.C; Simmer J.P; Kim J.W. Hypoplastic AI with highly variable expressivity caused by ENAM mutations. J. Dent. Res. 2018; 97(9): 1064-1069.

14. Seymen F; Lee K.E; Koruyucu M; Gencay K; Bayram M; Tuna E.B; Lee Z.H; Kim J.W. ENAM mutations with Incomplete Penetrance. J. Dent. Res. 2014; 93(10): 988-992.

15. Wang X; Zhao Y; Yang Y; Qin M. Novel ENAM and LAMB3 mutations in chinese families with hypoplastic amelogenesis imperfecta. Plos One. 2015; 10(3): e0116514.

16. Hart T.C; Hart P.S; Gorry M.C; Michalec M.D; Ryu O.H; Uygur C; Ozdemir D; Firatli S; Aren G; Firatli E. Novel ENAM mutation responsible for autosomal recessive amelogenesis imperfecta and localised enamel defects. J. Med. Genet. 2003; 40(12): 900-906.

17. Siddiqui S; Al-Jawad M. Enamelin directs crystallite organization at the enamel-dentine junction. J. Dent. Res. 2016; 95(5): 580-587.

18. Brookes S.J; Barron M.J; Smith C.E.L; Poulter J.A; Mighell A.J; Inglehearn C.F; Brown C.J; Rodd H; Kirkham J; Dixon M.J. Amelogenesis imperfecta caused by N-Terminal enamelin point mutations in mice and men is driven by endoplasmic reticulum stress. Hum. Mol. Genet. 2017; 26(10): 1863-1876.

19. Delsuc F; Gasse B; Sire J.Y. Evolutionary analysis of selective constraints identifies ameloblastin $(\mathrm{AMBN})$ as a potential candidate for amelogenesis imperfecta. BMC Evolutionary Biology. 2015; 15: 148.

20. Poulter J.A; Murillo G; Brookes S.J; Smith C.E.L; Parry D.A; Silva S; Kirkham J; Inglehearn C.F; Mighell A.J. Deletion of ameloblastin exon 6 is associated with amelogenesis imperfecta. Hum. Mol. Genet. 2014; 23(20): 5317-5324. 
21. Fukumoto S; Kiba T; Hall B; Iehara N; Nakamura T; Longenecker G; Krebsbach P.H; Nanci A; Kulkarni A.B; Yamada Y. Ameloblastin is a cell adhesion molecule required for maintaining the differentiation state of ameloblasts. J. Cell Biol. 2004; 167(5): 973-983.

22. Sire J.Y; Davit-Béal T; Delgado S; Gu X. The origin and evolution of enamel mineralization genes. Cells Tissues Organs. 2007; 186(1): 25-48.

23. Liang T; Hu Y; Smith C.E; Richardson A.S; Zhang H; Yang J; Lin B; Wang S.K; Kim J.W; Chun Y.H; Simmer J.P; Hu J.C.C. AMBN mutations causing hypoplastic amelogenesis imperfecta and Ambn knockout-NLS-laczknockin mice exhibiting failed amelogenesis and Ambn tissue-specificity. Mol. Genet. Genomic Med. 2019; 7(9): e929.

24. Lu T; Li M; Xu X; Xiong J; Huang C; Zhang X; Hu A; Peng L; Cai D; Zhang L; Wu B; Xiong F. Whole exome sequencing identifies an AMBN missense mutation causing severe autosomal-dominant amelogenesis imperfecta and dentin disorders. Int. J. Oral Sci. 2018; 10(3): 26.

25. Wang S.K; Zhang H; Hu C.Y; Liu J.F; Chadha S; Kim J.W; Simmer J.P; Hu J.C.C. FAM83H and autosomal dominant hypocalcified amelogenesis imperfecta. J. Dent. Res. 2021; 100(3): 293-301.

26. Urzua B; Martinez C; Ortega-Pinto A; Adorno D; Morales-Bozo I; Riadi G; Jara L; Plaza A; Lefimil C; Lozano C; Reyes M. Novel missense mutation of the FAM83H gene causes retention of amelogenin and a mild clinical phenotype of hypocalcified enamel. Arch. Oral Biol. 2015; 60(9): 1356-1367.

27. Wang S.K; Hu Y; Yang J; Smith C.E; Richardson A.S; Yamakoshi Y; Lee Y.L; Seymen F; Koruyucu M; Gencay K; Lee M; Choi M; Kim J.W; Hu J.C.C; Simmer J.P. Fam83h null mice support a neomorphic mechanism for human ADHCAI. Mol. Genet. Genomic Med. 2015; 4(1): 46-67.

28. Wang S.K; Hu Y; Smith C.E; Yang J; Zeng C; Kim J.W; Hu J.C.C; Simmer J.P. The enamel phenotype in homozygous Fam83h truncation mice. Mol. Genet. Genomic Med. 2019; 7(6): e724.

29. Zheng, Y; Lu T; Chen J; Li M; Xiong J; He F; Gan Z; Guo Y; Zhang L; Xiong F. The gain-of-function FAM83H mutation caused hypocalcification amelogenesis imperfecta in a chinese family. Clin. Oral Invest. 2021; 25(5): 2915-2923.

30. Xin W; Wenjun W; Man Q; Yuming Z. Novel FAM83H mutations in patients with amelogenesis imperfecta. Sci. Rep. 2017; 7(1): 6075.

31. Yu S; Quan J; Wang X; Sun X; Zhang X; Liu Y; Zhang C; Zheng S. A novel FAM83H mutation in one Chinese family with autosomal-dominant hypocalcification amelogenesis imperfecta. Mutagenesis. 2018; 33(4): 333-340.

32. Zhang C; Song Y; Bian Z; Ultrastructural analysis of the teeth affected with amelogenesis imperfecta resulting from FAM83H mutations and review of the literatures. Oral Surg. Oral Med. Oral Pathol. Oral Radiol. 2015; 119(2): e69-76.

33. Kuga T; Sasaki M; Mikami T; Miake Y; Adachi J; Shimizu M; Saito Y; Koura M; Takeda Y; Matsuda J; Tomonaga T; Nakayama Y. FAM83H and casein kinase I regulate the organization of the keratin cytoskeleton and formation of desmosomes. Sci. Rep. 2016; 6: 26557.

34. Gasse B; Prasad M; Delgado S; Huckert M; Kawczynski M; Garret-Bernardin A; Lopez-Cazaux S; Bailleul-Forestier I; Manière M.C; Stoetzel C; Bloch-Zupan A; Sire J.Y. Evolutionary analysis predicts sensitive positions of MMP20 and validates newly-and previously-identified MMP20 mutations causing amelogenesis imperfecta. Front. Physiol. 2017; 8: 398.

35. Wang S.K; Zhang H; Chavez M.B; Hu Y; Seymen F; Koruyucu M; Kasimoglu Y; Colvin C.D; Kolli T.N; Tan M.H; Wang Y.L; Lu P.Y; Kim J.W; Foster B.L; Bartlett J.D; Simmer J.P; Hu J.C.C. Dental malformations associated with biallelic MMP20 mutations. Mol. Genet. Genomic Med. 2020; 8(8): e1307.

36. Seymen F; Park J.C; Lee K.E; Lee H.K; Lee D.S; Koruyucu M; Gencay K; Bayram M; Tuna E.B; Lee Z.H; Kim Y.J; Kim J.W. Novel MMP20 and KLK4 mutations in amelogenesis imperfecta. J. Dent. Res. 2015; 94(8): 1063-1069.

37. Kim Y.J; Kang J; Seymen F; Koruyucu M; Zhang H; Kasimoglu Y; Bayram M; Tuna-Ince E.B; Bayrak S; Tuloglu N; Hu J.C.C; Simmer J.P; Kim J.W. Alteration of exon definition causes amelogenesis imperfecta. J. Dent. Res. 2020; 99(4): 410-418. 
38. Kim Y.J; Kang J; Seymen F; Koruyucu M; Gencay K; Shin T.J; Hyun H.K; Lee Z.H; Hu J.C.C; Simmer J.P; Kim J.W. Analyses of MMP20 missense mutations in two families with hypomaturation amelogenesis imperfecta. Front. Physiol. 2017; 8: 229.

39. Hu Y; Smith C.E; Richardson A.S; Bartlett J.D; Hu J.C; Simmer J.P. MMP20, KLK4, and MMP20/ KLK4 double null mice define roles for matrix proteases during dental enamel formation. Mol. Genet. Genomic Med. 2015; 4(2): 178-196.

40. Smith C.E.L; Kirkham J; Day P.F; Soldani F; mcderra E.J; Poulter J.A; Inglehearn C.F; Mighell A.J; Brookes S.J. A fourth KLK4 mutation is associated with enamel hypomineralisation and structural abnormalities. Front. Physiol. 2017; 8: 333.

41. Hart P.S; Hart T.C; Michalec M.D; Ryu, O.H; Simmons D; Hong S; Wright J.T. Mutation in kallikrein 4 causes autosomal recessive hypomaturation amelogenesis imperfecta. J. Med. Genet. 2004; 41(7): 545-549.

42. Wang S.K; Hu Y; Simmer J.P; Seymen F; Estrella N.M.R.P; Pal S; Reid B.M; Yildirim M; Bayram M; Bartlett J.D; Hu J.C.C. Novel KLK4 and MMP20 mutations discovered by whole-exome sequencing. J. Dent. Res. 2013; 92(3): 266-271.

\section{Nota contribución de los autores:}

1. Concepción y diseño del estudio

2. Adquisición de datos

3. Análisis de datos

4. Discusión de los resultados

5. Redacción del manuscrito

6. Aprobación de la versión final del manuscrito

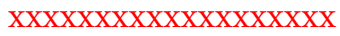

\section{Nota de aceptación:}

Este artículo fue aprobado por la editora de la revista Mag. Dra. Vanesa Pereira-Prado. 